\title{
Some subjects in developing the system of environmental radiation protection in Japan
}

\author{
I. Urabe ${ }^{1}$ and N. Sugiura ${ }^{2}$ \\ ${ }^{1}$ School of Engineering, Fukuyama University, Gakuen-cho 1, Fukuyama-shi, \\ Hiroshima 729-0292, Japan \\ ${ }^{2}$ Research Center for Nuclear Science and Technology, The University of Tokyo, 2-11-16, \\ Yayoi, Bunkyo-ku, Tokyo 113-0032, Japan
}

\begin{abstract}
The environmental radiation protection has been investigated on the basis of the radiological impacts on biota which are mainly caused by nuclear accidents, and the radiation doses of some plants and animals have been actually monitored in the natural environment. The investigation clearly shows that some radiological effects in the natural environment can be detected before the actual harmful effects occur, because the minimum radiation doses at which harmful effects have been observed are sufficiently high, compared with the radiation doses currently monitored in the natural environment. But, at the same time, it has been accepted that continuing investigations on the radiological effects on ecosystem are indispensable for the establishment of radiation protection system for biota to confirm that the environment has been properly protected from the potential exposure of radiation. The examinations of the risk perception of Japanese people also suggest that the communication with the public about the actual condition of the natural environment on the basis of the scientific data and the opinions of scientists of many fields is very important, because Japanese people tend to be extremely sensitive to the radiological effects on the natural environment.
\end{abstract}

\section{INTRODUCTION}

On account of increasing concerns for the change of the natural environment, it has become important to discuss on a basic framework for the radiological protection of the natural environment. So far, it has been believed that the radiological standards to protect man sufficiently will ensure that non-human species are also not put at risk [1]. But it has been pointed out that it is difficult to determine whether the environment is properly protected from potential impacts of radiation under different circumstances such as nuclear accidents, though it is generally accepted that there have hitherto been no apparent effects on plants and animals from the radiation exposure enhanced by human activities like normal operations of nuclear facilities [2]. So it is very important to discuss on the actual radiological condition of biota and to answer why the new radiation protection system based on the radiological impacts on non-human species is needed. This becomes more important because of its great impacts on social agreement of the utilization of radiations and nuclear energy.

From this point of view, we briefly review damages caused by acute radiation exposure based on the results of UNSCEAR and others [2 6] in order to know the dose level at which harmful radiation effects on biota were observed, and the dose rates below which harmful effects would not be expected. And the radiation doses of some plants and animals measured with the present method of environmental radiation monitoring are examined to make clear the actual radiological condition of the environment as well as to know effectiveness of the measuring system for detection of the harmful effects in biota. Some features of the Japanese attitude to the nature are also briefly discussed in order to know the appropriate way to answer the public concern on this problem. 


\section{ACUTE EFFECTS ON BIOTA}

From the viewpoint of the maintenance of biological diversity, the approach based on the harmful effects appeared in individual organism has been considered to be one of the effective ways to detect the ecological variation in the natural environment [7]. Radiation effects clarified in the biological investigations or by epidemiological survey in the area seriously contaminated by the large-scale accidents are useful to study dose-response relationships of plants and animals and to consider safety standards for protection of organisms in the natural environment.

The relationship between the effects on organisms and their radiation doses has been examined based on the reports of the UNSCEAR, etc [2 4]. It is concluded from the examination, firstly, that it took a long time to detect observable effects in the organisms caused by the continual radiation exposure, and secondly, that sensitivities of plants and animals to radiation exposure were lower than human species; as a result, lethal doses of them were generally higher than those of human species. And it may be emphasized that the effects in individual organism in the limited region of the environment would not be decisive to biota in the environment of a larger range. Examples of the minimum radiation doses that caused acute radiation damages to some organisms are shown in Table 1.

Table 1. Absorbed doses that cause acute effects to organisms in the natural environment.

\begin{tabular}{l|c|l|c}
\hline \multicolumn{1}{c|}{ Organism } & Absorbed dose(Gy) & \multicolumn{1}{|c}{ Radiobiological effects } & Ref. \\
\hline \hline Pine (Bud meristem) & $2-4$ & Desiccation of needles in the lower part of the crown & {$[3]$} \\
\hline $\begin{array}{l}\text { Coniferous trees } \\
\text { (needles) }\end{array}$ & $<10$ & Morphological disturbances & {$[3]$} \\
\hline Minnow eggs & 7.5 & Abnormality & {$[4]$} \\
\hline White leghorn chicken & 4.0 & Reducing egg production & {$[2]$} \\
\hline
\end{tabular}

It is apparent from Table 1 that the radiation damages are caused by the acute radiation exposure above a few Gy. On the assumption that the organisms are chronically irradiated in the natural environment, the radiation dose rates about tens of $\mathrm{mGy} / \mathrm{d}$ can be derived from the doses in Table 1 . This dose rate will be low enough to prevent the harmful effects by radiation exposure. Thus, a radiation dose rate below about $10 \mathrm{mGy} / \mathrm{d}$ will be appropriate to protect an individual plants and animals. U.S. DOE has introduced the dose limits for aquatic animals and terrestrial plants, $10 \mathrm{mGy} / \mathrm{d}$, and for terrestrial animals, $1 \mathrm{mGy} / \mathrm{d}$. IAEA has reported that harmful effects on aquatic life or terrestrial plants population have not been observed by chronic exposures below $10 \mathrm{mGy} / \mathrm{d}$, and that the dose rates less than $1 \mathrm{mGy} / \mathrm{d}$ have not caused harmful effects on terrestrial animal population. This guidelines are provided only in dose rate. Even though the probability might be low, the guideline of the dose below $1 \mathrm{~Gy} / \mathrm{event}$ is necessary to protect biota from the acute radiation damages.

\section{PRESENT STATUS OF ENVIRONMENTAL RADIATION MONITORING IN JAPAN}

The present system of environmental radiation monitoring in Japan has been established following the ICRP recommendations. Its objectives are (1) to estimate radiation doses of the public around nuclear facilities, (2) to understand the long-term accumulation of radioactive materials in the natural environment, (3) to contribute to the judgment of the possibility of the harmful effects caused by the unexpected release of radioactive materials into the surroundings of nuclear facilities [6]. The variation of environmental radioactivities has been monitored considerably in detail. Especially, the measurements based on the second objective have been playing an important role to know the movement of radioactivities in the natural environment because they have been carried out based on the actual sampling of environmental sample such as soil, water, indicator organisms, etc.

The radioactivities in the environmental samples, though they are selected from the viewpoint of the exposure of human beings, may be useful to discuss the detection ability of the present system of the environmental radiation monitoring. Some examples of indicator organisms and their radioactivities of and doses due to ${ }^{137} \mathrm{Cs}$ are shown in Table 2 together with those of natural radioactivities. 
Table 2. Absorbed doses of estimated from the radioactivities determined by the environmental radiation monitoring.

\begin{tabular}{l|l|c|c}
\hline Radionuclide & Organism & Activity $(\mathrm{Bq} \mathrm{kg}$ & Absorbed dose $\left(\mu \mathrm{Gy} \mathrm{y}^{-1}\right)$ \\
\hline \hline Cs-137 & Sea fish (Ibaraki) & $0.2 \sim 0.4$ & 2 \\
\hline & Seaweed (Ibaraki) & $0.1 \sim 0.3$ & 7 \\
\hline & Sweet potato (Ibaraki) & 1 & 20 \\
\hline & Cabbage & 0.1 & 30 \\
\hline K-40 & Vegetables & 100 & 40 \\
\hline Ra-226 & Japanese cedar & 0.3 & 160 \\
\hline
\end{tabular}

It is apparent from Table 2 that the radioactivities corresponding to several tens of $\mu \mathrm{Gy} / \mathrm{y}$ can be determined easily by the present method used for the environmental monitoring. Thus, it is quite possible to evaluate the variation of radioactivities in the natural environment, before the harmful effects on the plants and animals including the reference organisms selected for protection of non-human species are evidently observed.

It is apparent from the comparison of the doses in Table 2 with international guideline, $10 \mathrm{~m}$ Gy/d, that the radiation doses of the terrestrial plants due to ${ }^{137} \mathrm{Cs}$ and $\mathrm{BG}$ radioactivities are at least 3 orders of magnitude less than the protection standards proposed by DOE and IAEA. So it can be expected that the radiation dose of indicator organisms is detected enough below the protection standards, although the radiation effects depends on the sensitivity to radiation, the wide variety of distribution characteristics of the radioactivities, the differences of the concentration factor of plants and animals and so forth.

However, it is also important to recall that the knowledge about the natural environment is still limited and the data about the radiological impacts on biota is insufficient to determine the indicator organism representing the tendency of the critical variation of the natural environment [8]. Because it is very difficult to make sure that the natural environment will be completely protected from the radiological impacts caused by human activities, continuous investigations on the radiological effects on plants and animals or ecosystem and on the monitoring system of radioactivities are indispensable for the establishment of radiation protection system for biota.

\section{FEATURES OF THE JAPANESE UNDERSTANDING OF THE NATURE}

It is commonly accepted that Japanese people were accustomed to have their lives by making use of the nature effectively because they were engaged in the agricultural production for a long time. Such life required them to pay an attention to the change of the natural environment. So Japanese people often felt the change of the season to be a part of their daily life and they accepted the results as a given one, even the bad results of the natural inevitable disasters and, at the same time, they showed their thanks to the nature in the case of good harvests. However, it is also said that Japanese people had not been trained to understand the change of the natural environment scientifically because they perceived sensuously the cause of its variations [9].

With the industrialization of the country, the environmental problems like air and water pollutions became realised and the interest for the environmental risks has been increased rapidly. In addition, growing of environmental problems in recent years has caused the remarkable separation of the people into two groups depending on their risk perception [10]. That is, they are sharply divided into two groups: one tends to accept the environmental risk and the other tends to deny it. It is probably because their decision making of acceptance or denial greatly depends on the offered information as well as on the individual historical background.

In Japan, it is said that the people have not paid much attention to the radiological protection of the natural environment. This is because they take the safety of the natural environment for granted since they have not observed any remarkable adverse effects on living organisms in the natural environment owing to the successful management by the civil services etc against the increments of radiation exposure. So, it is important to show them the purpose and significance of the both systems of the natural environmental monitoring, that is, the present system and the new environmental radiation protection 
system based on the protection of non-human species. If Japanese people receive the environmental radiation protection program without understanding the reason why it is needed, they will tend to consider that this issue must be taken up by the actual occurrence of the contamination of radioactivities in the natural environment and they will tend to be extremely sensitive to the radiological effects on the natural environment, not only from scientific viewpoint but also from their ethical and political viewpoints, which will be inevitably affected by the news released by mass media.

Japanese people are generally critical to the action, which causes the trouble to the people of the circumference. The people also tend to expect the control of the environmental risk by the national regulation in the situation where the adverse effect appears in the environment [11]. In order to consider the system of the environmental radiation protection it is very important to continue fundamental investigation to know the possibility of the occurrence of adverse radiation effects on biota and its effects to the structure of the ecosystem including human species and it is also very important to communicate with the public including stakeholders about the actual condition of the natural environment on the basis of the opinions of the scientists of many fields [12].

\section{CONCLUSIONS}

Our conclusions from these discussions are as follows:

(1) The radiation dose rates in biota below about $10 \mathrm{mGy} / \mathrm{d}$ and $1 \mathrm{~Gy} /$ event will be appropriate to protect an individual plants and animals because the harmful effects will be observed as a result of prolonged exposure and low probability of acute irradiation in the natural environment.

(2) It can be expected that the radiation dose of reference plants and animals estimated by the present system of environmental radiation monitoring for nuclear facilities will be sufficiently below the international guideline proposed by DOE and IAEA.

(3) Because it is very difficult to make sure that the natural environment is properly protected from the radiological effects due to human activities, continuous investigations about the radiological effects on plants and animals or ecosystem are indispensable for the establishment of radiation protection system for biota.

(4) It is very important to communicate with the public including stakeholders about the actual condition of the natural environment on the basis of the scientific and technological data and the opinions given by scientists of many fields.

\section{Acknowledgements}

This research was carried out by the Task Group of the Committee for the Standardization of Radiation Protection established by the Nuclear Safety Research Association. The authors wish to thank to the members of the Task Group for Development of Framework of Environmental Radiation Protection.

\section{References}

[1] ICRP, Annals of the ICRP 21(1-3), (1990).

[2] IAEA, Technical Report Series No.332 (1992).

[3] UNSCEAR, UNSCEAR Report to the General Assembly, with Scientific Annex, (1996).

[4] W. L. Templeton, in Radiation Effects on Aquatic Organisms, edited by N. Egami (Japan Scientific Scieties Press, Tokyo University Park Press, 1980)

[5] NRPB, Radiological Protection Bulletin No.212, 5-8 (1999)

[6] NSRA, in Environmental Radiation Monitoring, Practical Textbook Series No.4, (NSRA, 1987)

[7] IAEA, IAEA-TECDOC-1270, (2002)

[8] FASSET, FASSET Contract No FIGE-CT-2000-00102, (2002).

[9] K. Mizushima, J. J. Risk Analysis 14 (1), 51-58 (2002)

[10] H. Hirose, ibid. 9 (1), 21-23 (1997).

[11] S. Tsuchida, ibid. 9 (1), 96-104 (1997)

[12] H. Ohtsubo, A. Yamamoto and T. Kikkawa, ibid. 14 (1), 63-68 (2002). 